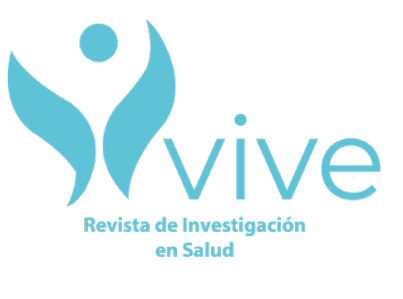

VIVE. Revista de Investigación en Salud https://revistavive.org Volumen 4 No. 12 septiembre-diciembre 2021 https://doi.org/10.33996/revistavive.v4i12.114 ISSN: 2664-3243 pp. 571 - 579

\title{
Protocolo para la administración de plasma hiperinmune a pacientes covid-19
}

\author{
Protocol for the administration of plasma hyperimmune to covid-19 patients
}

Protocolo para a administração de plasma hiperimuna para pacientes covid-19

\author{
Danilo Maida Díaz \\ danilomaida22@gmail.com \\ https://orcid.org/0000-0003-4922-1819 \\ Master en Medicina Transfusional, Especialista en Hemoterapia, \\ Hospital “Presidente Germán Busch", Trinidad, Beni, Bolivia \\ Universidad Autónoma del Beni “José Ballivián”, Trinidad-Beni-Bolivia \\ Recibido 4 de agosto 2021 / Arbitrado y aceptado 16 de septiembre 2021 / Publicado 30 de diciembre 2021
}

\begin{abstract}
RESUMEN
La transfusión de plasma hiperinmune o convaleciente en pacientes internados, es un problema en la actualidad porque existe desconocimiento de protocolos donde se determine la cuantificación de anticuerpos, tipo de donante, método de obtención y momento de administración. Objetivo. Elaborar un protocolo de administración de plasma hiperinmune en pacientes Covid-19, internados en el Hospital “Presidente Germán Busch” de Trinidad, gestión 2020. Materiales y métodos. Investigación descriptiva, se realizó una encuesta y revisión documental a población de 26 personales de salud y 25 pacientes respectivamente. Resultados. El desconocimiento de protocolos por parte del personal de salud fue de $73,1 \%$, considerando que el $61 \%$ cuentan con postgrados. De los pacientes transfundidos el $60 \%$ fallecieron, siendo de la tercera edad, sexo masculino y en estado crítico. El $28 \%$ fueron dados de alta hospitalaria, tomando en cuenta que fueron transfundidos en estado moderado. Conclusiones. El porcentaje de desconocimiento de protocolo de administración de plasma hiperinmune y los fallecimientos de pacientes transfundidos son elevados, es por ello que se propone la elaboración de un protocolo de administración de plasma hiperinmune para pacientes Covid-19, que se caracterice por: estudio previo de los donantes, método de obtención, títulos de anticuerpos y momento de administración del hemocomponente.
\end{abstract}

Palabras clave: Protocolo; Plasma hiperinmune; Hemocomponente; Transfusión; Anticuerpos

\begin{abstract}
Transfusion of hyperimmune or convalescent plasma in hospitalized patients is currently a problem because there is a lack of knowledge of protocols to determine the quantification of antibodies, type of donor, method of obtaining and time of administration. Objective. To develop a protocol for the administration of hyperimmune plasma in Covid-19 patients, admitted to the Hospital "Presidente Germán Busch" in Trinidad, management 2020. Materials and methods. Descriptive research, a survey and documentary review were carried out on a population of 26 health personnel and 25 patients respectively. Results. Lack of knowledge of protocols by health personnel was $73.1 \%$, and $61 \%$ have postgraduate degrees. Of the transfused patients, $60 \%$ died, being elderly, male and in critical condition. $28 \%$ were discharged from hospital, taking into account that they were transfused in moderate condition. Conclusions. The percentage of ignorance of the hyperimmune plasma administration protocol and the deaths of transfused patients are high, which is why the development of a hyperimmune plasma administration protocol for Covid-19 patients is proposed, characterized by: study previous donor, method of obtaining, antibody titers and time of administration of the blood component.
\end{abstract}

Key words: Protocol; Hyperimmune plasma; Hemocomponent; Transfusion; Antibodies 


\section{RESUMO}

A transfusão de plasma hiperimune ou convalescente em pacientes hospitalizados é atualmente um problema, pois há falta de conhecimento de protocolos para determinar a quantificação de anticorpos, tipo de doador, método de obtenção e tempo de administração. Objetivo. Desenvolver um protocolo para a administração de plasma hiperimune em pacientes Covid-19, internados no Hospital "Presidente Germán Busch" em Trinidad, gestão 2020. Materiais e métodos. Pesquisa descritiva, levantamento e revisão documental foram realizados em uma população de 26 profissionais de saúde e 25 pacientes, respectivamente. Resultados. O desconhecimento dos protocolos por parte dos profissionais de saúde foi de $73,1 \%$, e $61 \%$ possuem pós-graduação. Dos pacientes transfundidos, $60 \%$ morreram, sendo idosos, do sexo masculino e em estado crítico. $28 \%$ tiveram alta hospitalar, levando-se em consideração que foram transfundidos em estado moderado. Conclusões. O percentual de desconhecimento do protocolo de administração de plasma hiperimune e os óbitos de pacientes transfundidos são elevados, razão pela qual é proposto o desenvolvimento de um protocolo de administração de plasma hiperimune para pacientes com Covid-19, caracterizado por: estudo de doador prévio, método de obtenção, títulos de anticorpos e tempo de administração do hemocomponente.

Palavras-chave: Protocolo; Plasma hiperimune; Hemocomponente; Transfusão; Anticorpos

\section{INTRODUCCIÓN}

Durante el primer trimestre del año 2020 se presenta una situación poco común debido a su naturaleza, origina una escalada mundial de contagios, siendo considerado como una crisis mundial, esta es producida por un virus de la familia coronavirus SARS-COV-2 causante del Covid-19 (1). Esta cepa está infectando gran cantidad de personas alrededor del mundo (2). Dándose flexibilidades para que la comunidad científica conduzca ensayos clínicos con terapias de potencial utilidad, como la transfusión de plasma hiperinmune (TPH) provenientes de pacientes que vencieron la enfermedad Covid-19.
Los estudios recientes sobre la eficacia clínica de este tratamiento en enfermedades causadas por otros coronavirus SARS y MERS, evidencian la mejoría clínica con el aumento de anticuerpos neutralizantes que evitan la mortalidad y disminuyen los eventos adversos durante y después del tratamiento (3). En el caso del Covid-19, la Administración de alimentos y medicamentos de los EE.UU. (FDA por sus siglas en inglés) emitió: "una autorización donde se aprueba el uso de plasma de pacientes recuperados para para tratar a personas que estén gravemente enfermas con Covid-19, como un tratamiento compasivo y experimental" (4).

La inmunoterapia involucra la administración de anticuerpos contra un determinado agente patógeno en un individuo susceptible, con el propósito de prevenir, disminuir o tratar una infección causada por dicho agente como el SARS-COV-2 (5). Este procedimiento es válido cuando no se cuenta con inmunoglobulinas de manufactura más complejas como son las vacunas, siendo el único posible recurso el plasma hiperinmune de pacientes que hayan vencido el Covid-19 (6).

La Organización Mundial de la Salud (OMS) declara que el brote de Covid-19 constituye una emergencia de salud pública de preocupación a nivel mundial. El 11 de marzo de 2020, la OMS declara oficialmente la PANDEMIA (7). Bolivia reportó sus dos primeros casos confirmados el 10 de marzo de 2020 en los departamentos de Oruro y Santa Cruz; actualmente los 9 departamentos del país presentan casos de Covid-19, siendo los 
más afectados los departamentos de Santa Cruz, La Paz, Beni y Cochabamba (8).

Durante la emergencia sanitaria, el Hospital "Presidente Germán Busch" es referido como Centro "Covid-19" atendiéndose a todos los pacientes de las provincias, donde la mayoría son sometidos a respiradores de ventilación mecánica, tratamientos convencionales y transfusiones de plasmas hiperinmunes. En la práctica diaria, se observa el ingreso de pacientes Covid-19 con muchas complicaciones pulmonares y con síndrome de dificultad respiratoria aguda, donde el recurso es aplicar transfusiones de plasmas hiperinmunes. De ahí radica el objetivo e importancia en profundizar los riesgos y beneficios de las TPH, reflejándose en un protocolo, con el propósito de disminuir la estancia hospitalaria y mortalidad de pacientes con Covid-19.

\section{MATERIALES Y MÉTODOS}

Se realizó una investigación descriptiva, de campo, de corte transversal y retrospectivo. Se utilizaron métodos teóricos (dialéctico, histórico - lógico, deductivo, análisis-síntesis, modelación y estructural-funcional); métodos empíricos (revisión documental, encuesta y observación) y métodos estadísticos para el procesamiento de la información y resultados (9). La población de estudio estuvo constituida por 26 personal de salud: 9 médicos y 17 Licenciadas en Enfermería y 25 pacientes de 34 a 78 años, internados en los servicios de emergencia, medicina interna y terapia intensiva del Hospital "Presidente Germán Busch" de la ciudad de Trinidad, durante los meses de mayo a septiembre del 2020. Al personal de salud se aplicó la encuesta y se revisaron los historiales médicos y reportes de transfusión a los pacientes.

\section{RESULTADOS Y DISCUSIÓN}

Una vez adquirida la información se tabularon los datos procediendo al análisis, mismo que serán reflejados en los siguientes resultados:

El Gráfico 1 muestra que la totalidad del personal de salud tiene formación académica en posgrado, el $38,5 \%$ diplomados, un $30,8 \%$ cuentan con maestrías. Este dato es importante porque al tratarse de un hospital de tercer nivel, tienen que contar con recursos humanos calificados en su área. 


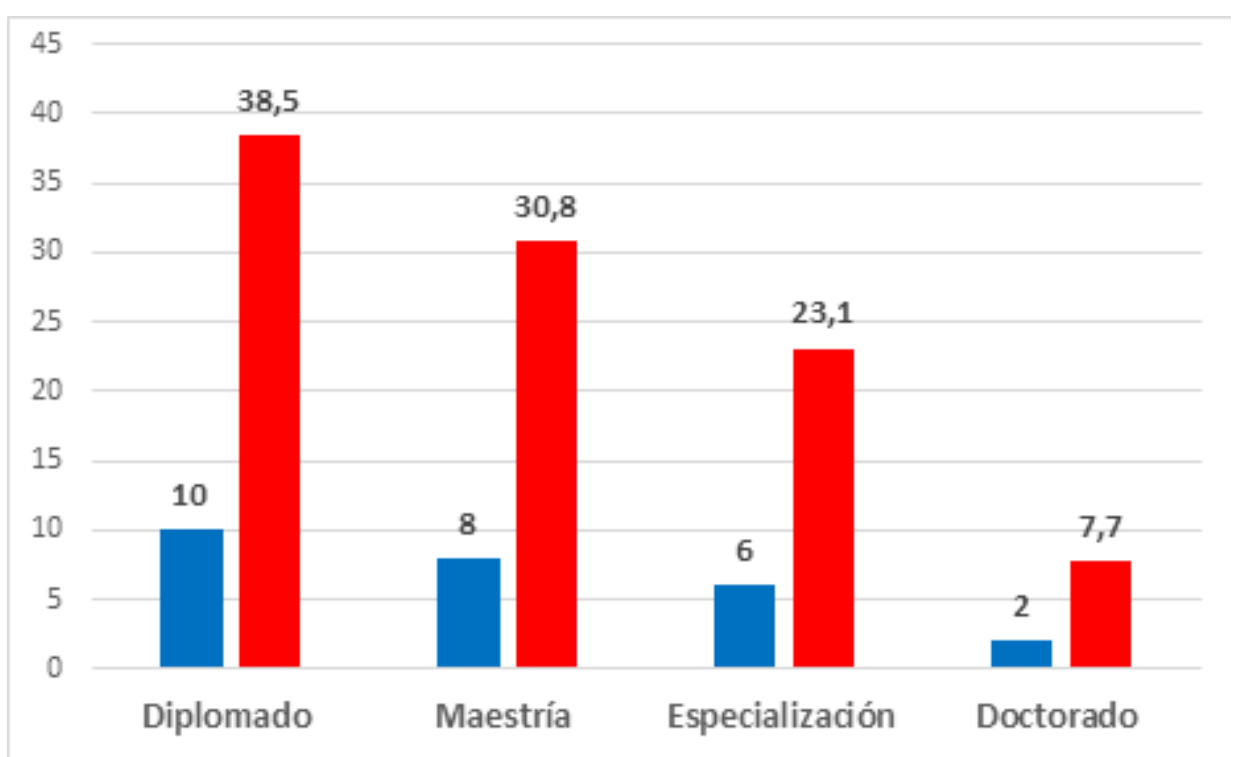

Gráfico 1. Nivel académico del personal de salud que fueron encuestados.

Más del $70 \%$ del personal de salud indicaron que no saben de la existencia de un protocolo de transfusión de plasma hiperinmune, este dato es preocupante porque no se pueden unificar criterios en los profesionales con procedimientos de transfusiones de plasmas hiperinmunes a pacientes Covid-19 según las normas estandarizadas (Gráfico 2).

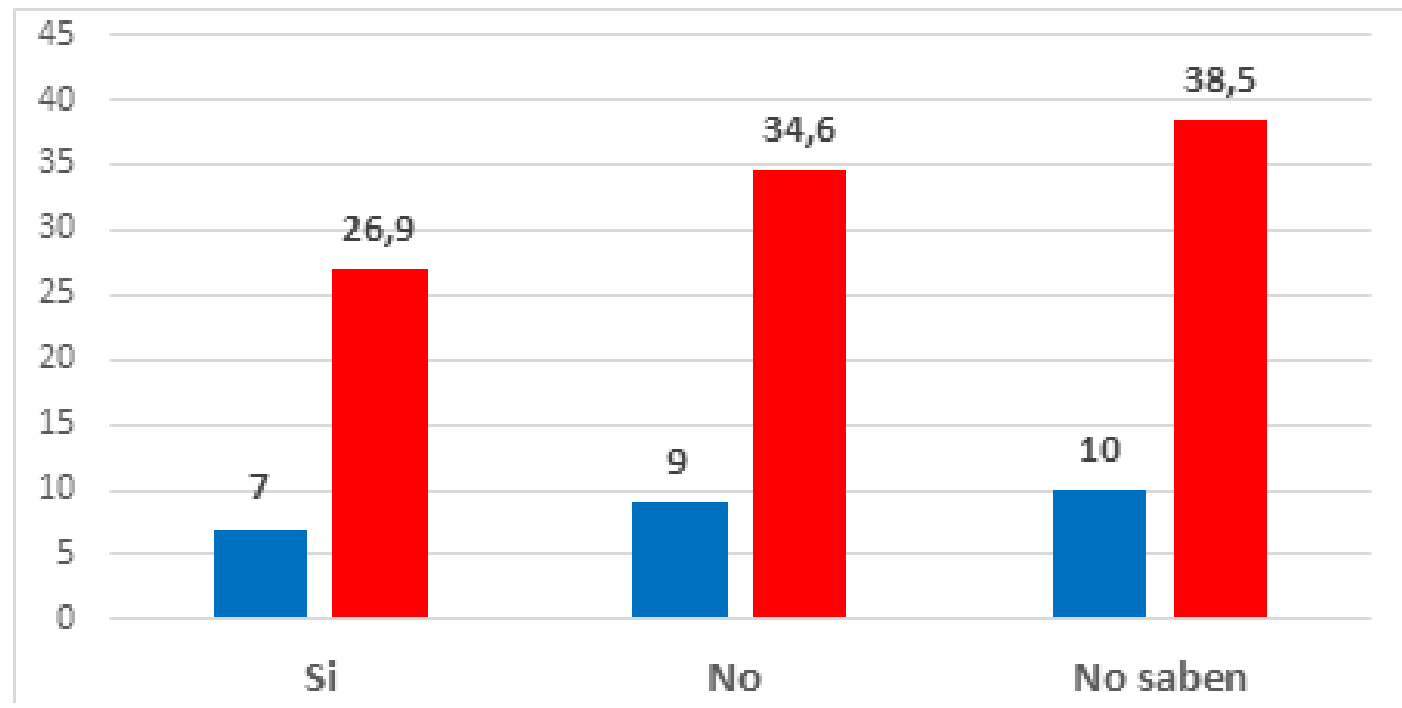

Gráfico 2. Conocimiento del personal sanitario sobre la existencia de protocolo de transfusión.

Se observó que la mayor ocupación de los pacientes Covid-19, fueron los profesionales en salud con $44,0 \%$, esto se debe a que están expuestos con frecuencia al entorno y por lo tanto tienen mayor riesgo de contagio (Gráfico 3). 


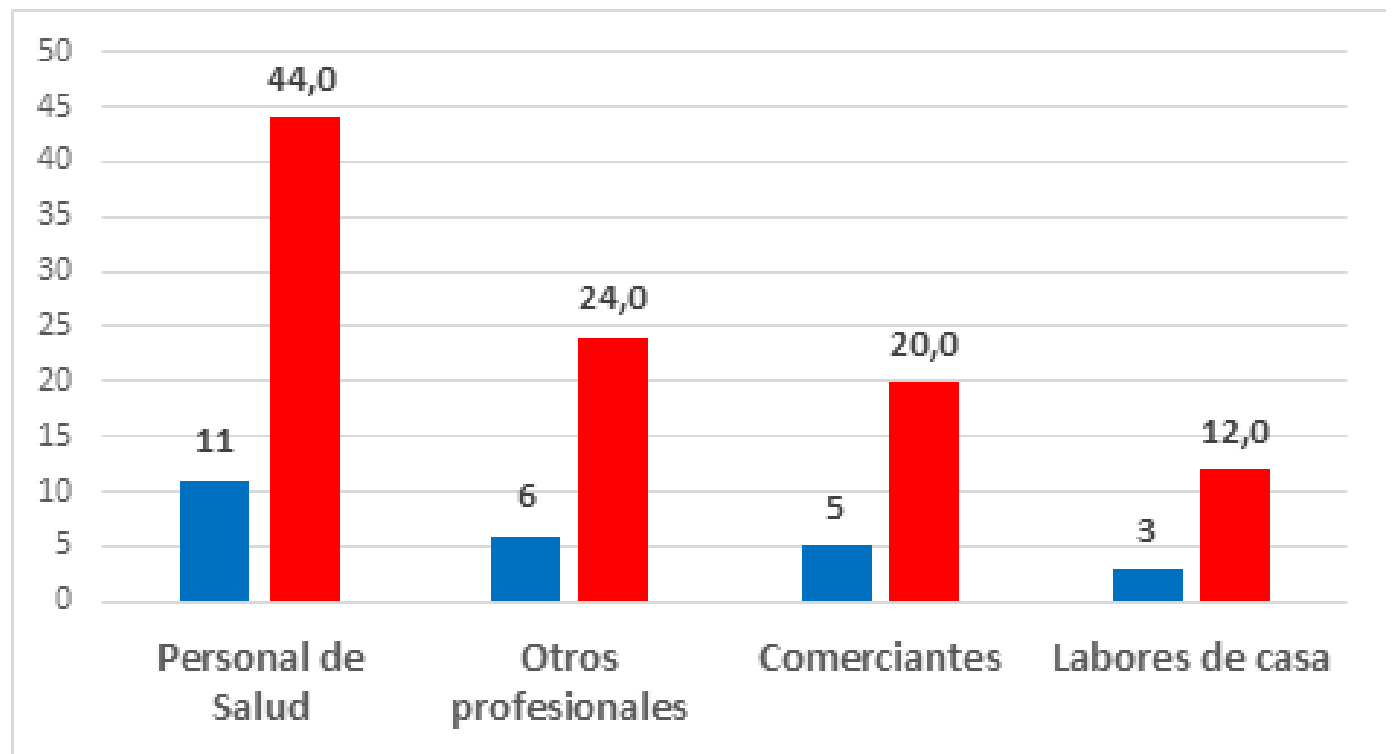

Gráfico 3. Ocupación de pacientes con Covid-19 que recibieron plasma hiperinmune.

Se evidenció que el 40,0\% del manejo crítico, por el colapso sanitario el servicio de inicial de pacientes Covid-19, fue en el servicio Emergencia cumplía funciones como unidad de Terapia Intensiva, debido a que la mayoría de cuidados intensivos (Gráfico 4). de pacientes llegaban en estado grave a

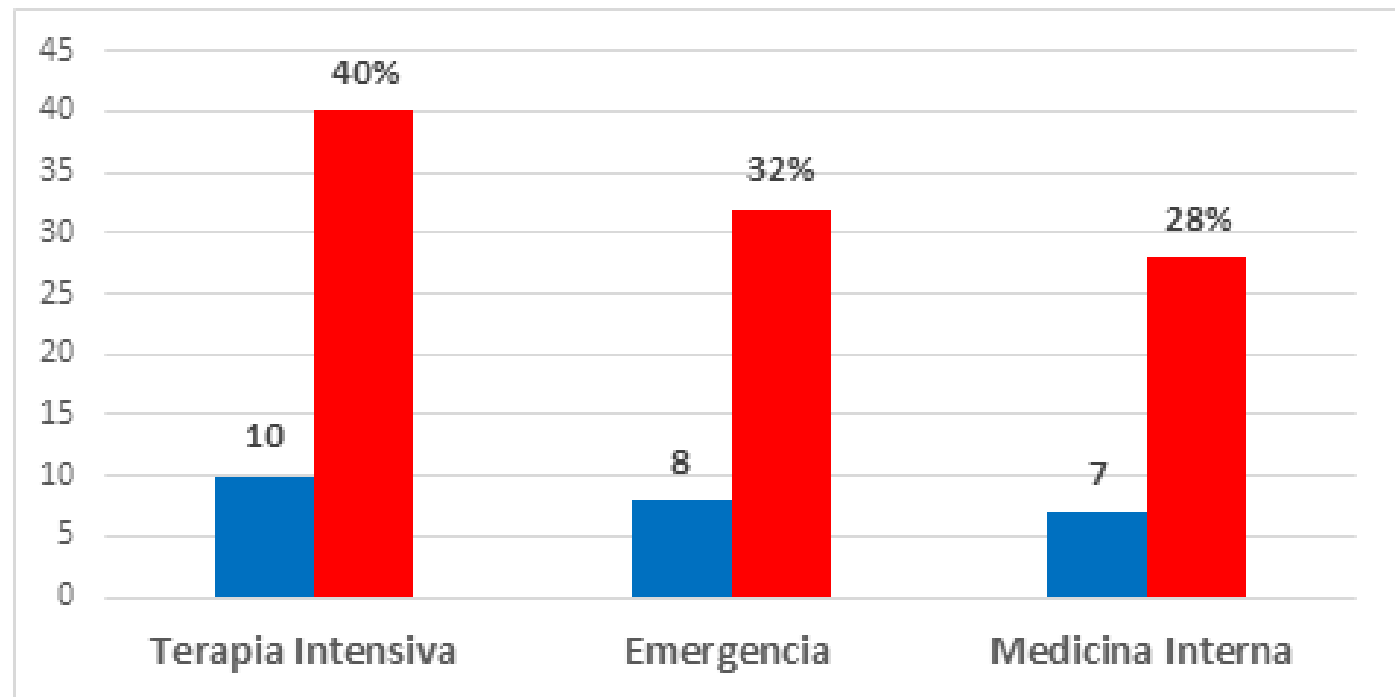

Gráfico 4. Manejo inicial de los pacientes con Covid-19 tratados con plasma hiperinmune.

El $60,0 \%$ de pacientes que recibieron de pacientes fueron dados de alta hospitalaria, plasma hiperinmune llegaron a fallecer por la es decir que llegaron a vencer la enfermedad gravedad y estado crítico de salud, un 28,0\% (Gráfico 5). 


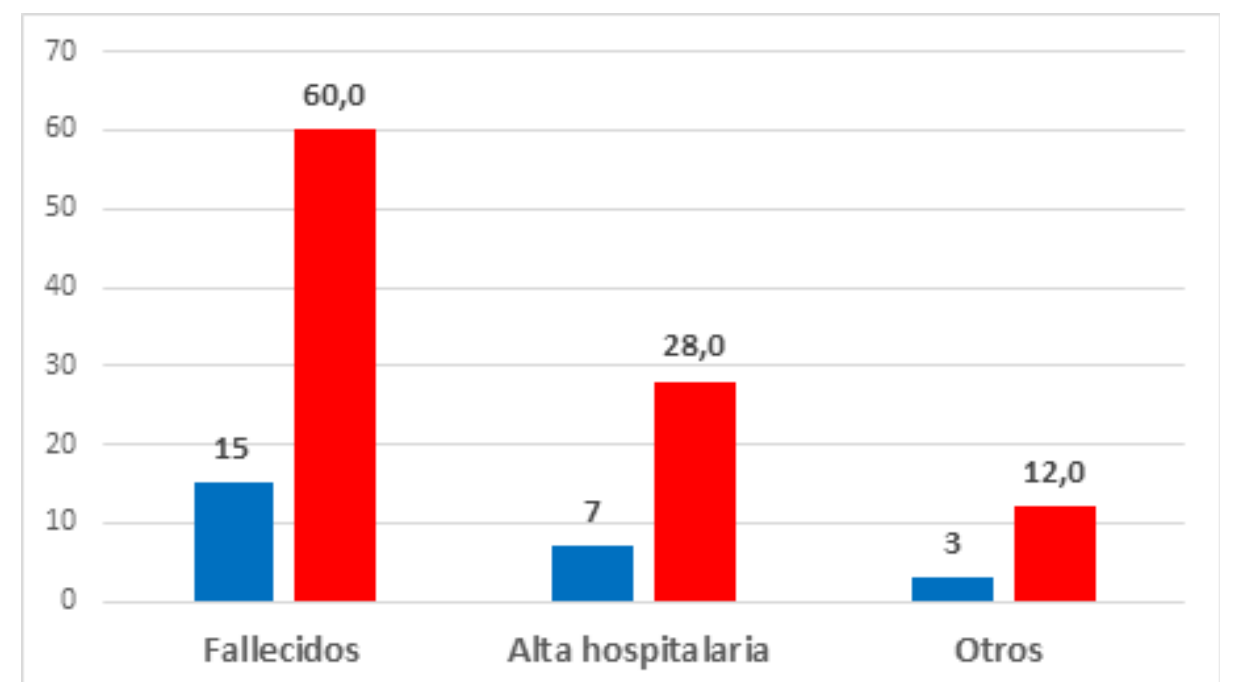

Gráfico 5. Desenlace general de pacientes Covid-19 tratados con plasma hiperinmune.

Del total de pacientes fallecidos por Covid-19 que se muestran en Gráfico 6, el 60,0\% fueron de la tercera edad entre 61 a 78 años, el $20,0 \%$ entre 50 a 60 años, esto nos mostró que existe un alto porcentaje de mortalidad en pacientes de la tercera edad, determinando que la edad influyó en el desenlace de los pacientes con Covid-19.

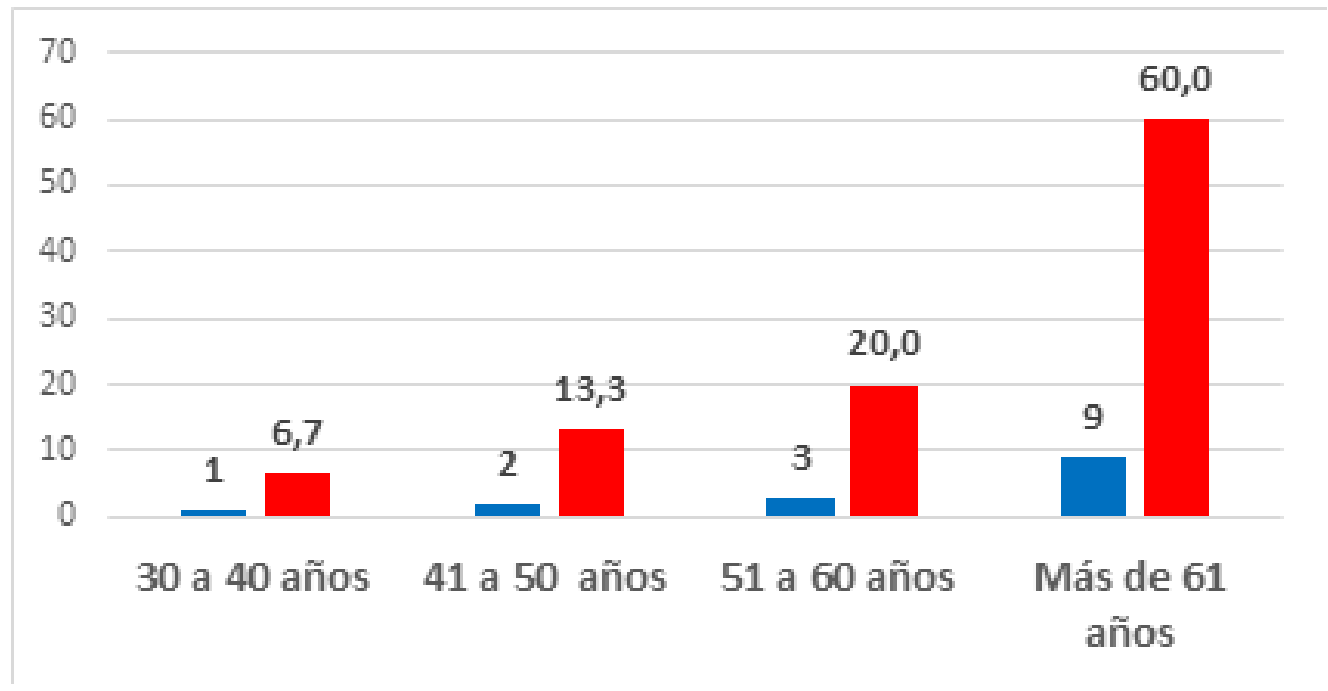

Gráfico 6. Grupo etario de los pacientes fallecidos por Covid-19 que fueron tratados con plasma hiperinmune.

En cuanto al sexo masculino la proporción de pacientes fallecidos fue mayor con un $73,3 \%$, el $57,1 \%$ fueron dados de alta hospitalaria. En cuanto al sexo femenino se observa un $26,7 \%$ de las pacientes fallecieron, un $42,9 \%$ fueron dadas de alta hospitalaria. Los datos observados muestran claramente que el mayor porcentaje de fallecidos es del sexo masculino (Gráfico 7). 


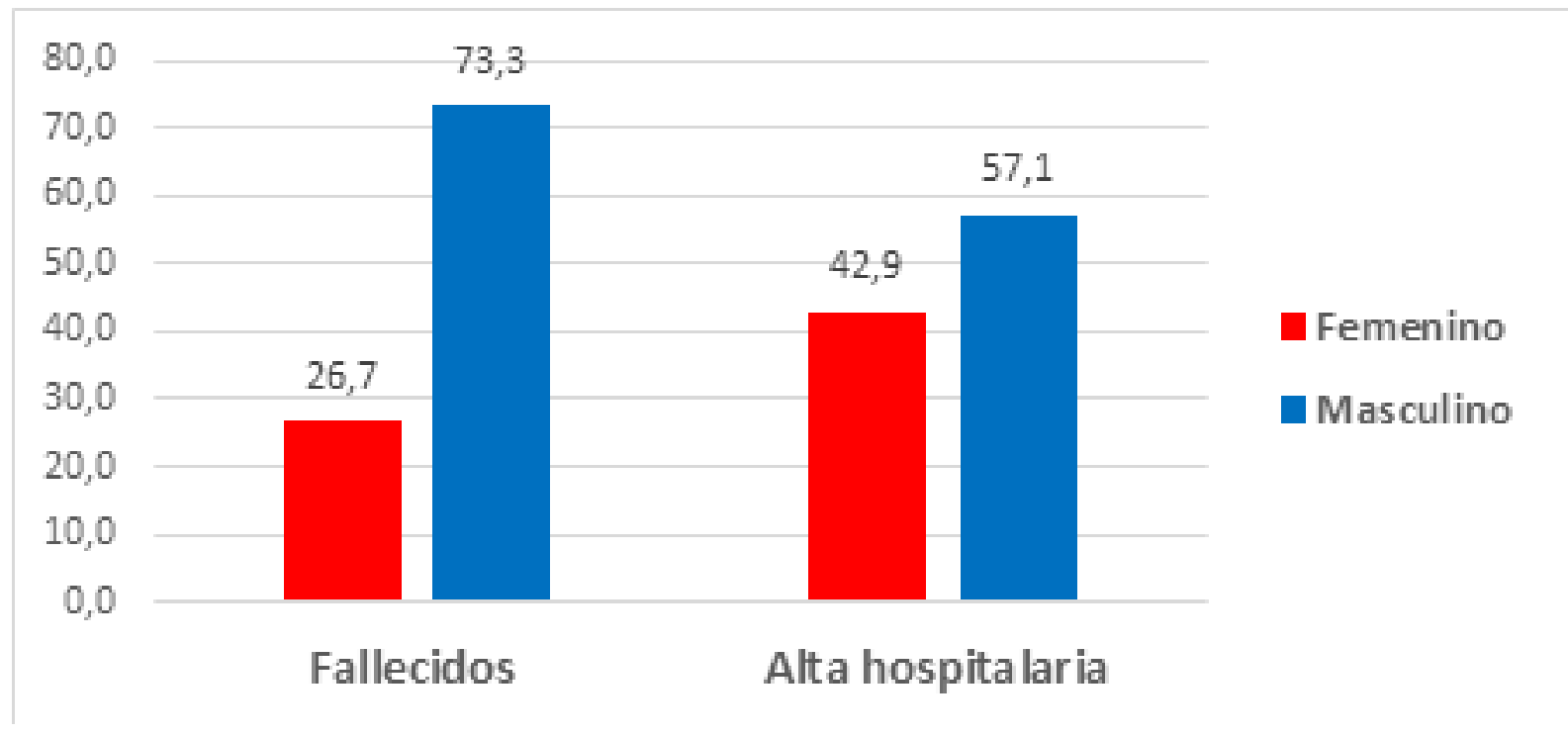

Gráfico 7. Desenlace de pacientes Covid-19 tratados con plasma hiperinmune, según sexo.

El desenlace de los pacientes tratados de plasma hiperinmune, mientras que los con plasma hiperinmune según la severidad, pacientes en estado moderado fueron dados muestran que al evaluar los 25 pacientes dealtahospitalaria, esto quiere decir que juega transfundidos, se encuentran que la totalidad un papel importante el estado de severidad a de los pacientes en estado crítico llegaron a la hora de realizar la transfusión del plasma fallecer pese a que se le realizó la transfusión hiperinmune para que haga efecto (Gráfico 8).

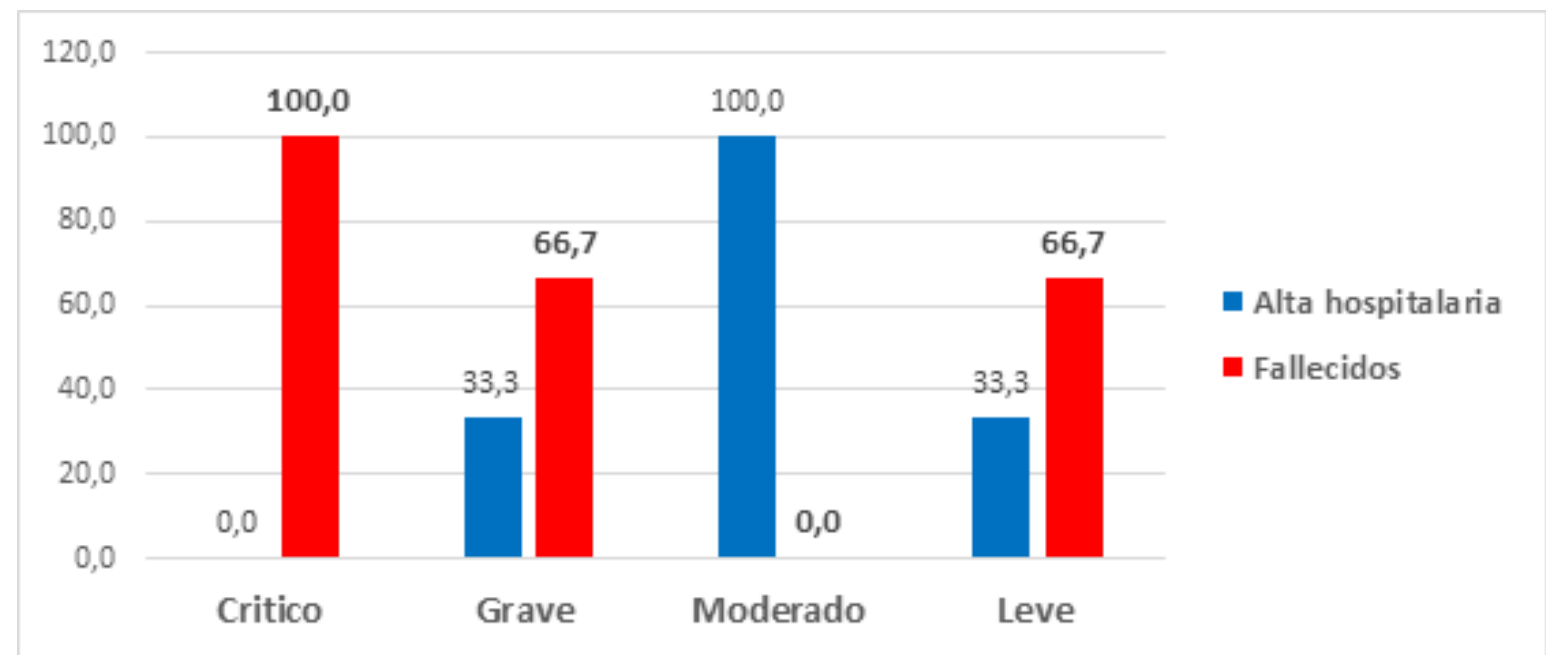

Gráfico 8. Desenlace de los pacientes con Covid-19 tratados con plasma hiperinmune según severidad. 


\section{Discusión}

Este estudio fue realizado en la Ciudad de Trinidad, Beni-Bolivia. El estudio arroja resultados aproximados sobre la situación actual de los conocimientos en protocolo de admiración, características, proceso de transfusión y sobre todo momento de administración del plasma hiperinmune, en pacientes entre edades de 34 a 78 años internados en el Hospital "Presidente Germán Busch" tomando en cuenta ciertas limitantes o condiciones que predisponen al desconocimiento de protocolos y mortalidad en pacientes Covid-19.

Tomando en cuenta, que el hospital es considerado de tercer nivel, se observó que el personal de salud; médicos y enfermeros tienen desconocimiento de la existencia de protocolo de transfusión de hemocomponentes, pese a tener posgrados; doctorados, maestrías, especialidades y diplomados, además de contar con años de experiencia. Este dato es importante, porque a pesar que son profesionales en salud y tener una amplia formación académica, demuestra que existe deficiencia en cuanto a los procedimientos transfusionales, por ende, los datos de la investigación es el reflejo de la realidad. El profesional de salud en medicina transfusional no solo tiene que tener años experiencia, formación académica, sino que también, contar con conocimientos sobre las normativas de procedimientos, constantes capacitaciones, experiencia en el área y sobre todo tener conocimientos en protocolos de administración de hemocomponentes.
Un alto porcentaje de los pacientes internados y que recibieron plasma hiperinmune durante el periodo de estudio son personal de salud, probablemente porque son ellos que están expuestos de forma constante con el virus y con los pacientes internados, por lo tanto, tienen mayor riesgo de contagio. El manejo inicial de los pacientes se realizó en los servicios de terapia intensiva y emergencia, esto tiene relación al estado crítico de los pacientes, cabe señalar que tanto el servicio de emergencia y medicina interna cumplían funciones como terapia intensiva, ya que no existían camas disponibles y el espacio quedaba reducido para la cantidad de pacientes que ingresaban. El alto porcentaje de mortalidad en pacientes que recibieron el plasma hiperinmune, puede atribuirse a que las transfusiones se realizaban a pacientes de la tercera edad y en estado crítico, además las características del componente sanguíneo no contaban con cierta características como la cantidad de anticuerpos necesarios y que a diferencia de otros departamentos, el método de obtención era muy limitante, es decir, reducida cantidad de donantes de sangre, para donar tenían que cumplir con dos pruebas PCR negativas, retraso en la entrega de los resultados laboratoriales y el método de obtención del plasma hiperinmune era por centrifugación y gravedad, el convencional. Los datos mostraron malos resultados cuando se administraban a pacientes en estado crítico y buenos resultados cuando se realizaban la transfusión en estado moderado. 


\section{CONCLUSIONES}

En concordancia con el objetivo planteado, se propone la elaboración de un protocolo para la administración de plasma hiperinmune en pacientes Covid-19, que se caracterice por: estudio previo de los donantes, método de obtención, títulos de anticuerpos y momento de administración del hemocomponente, con el propósito de disminuir la alta tasa de mortalidad que se observó en el presente estudio, en los pacientes de la tercera edad, sexo masculino y en estado crítico. Según los resultados obtenidos, recomienda realizar las transfusiones en fases tempranas del Covid-19, principalmente en estados moderados de la enfermedad, previa investigación clínica respectiva. Es relevante realizar estudios posteriores en un número mayor de pacientes Covid-19, de manera que se determine con exactitud la calidad del plasma hiperinmune antes y después de la transfusión y realizar controles al receptor por un tiempo prudente para determinar la inmunidad postransfusional.

\section{REFERENCIAS BIBLIOGRÁFICAS}

1. Centro para el Control y Prevención de Enfermedades. COVID-19. [Online]; 2020 [cited 2021 Abril. Available from: https://espanol.cdc. gov/coronavirus/2019-ncov/index.html.

2. Infosalus. ¿Por qué el SARS-COV-2 es mucho más infeccioso que el SARS-COV-1? [Online]; 2021 [cited 2021 Marzo. Available from: https:// www.infosalus.com/salud-investigacion/ noticia-sars-cov-mucho-mas-infeccioso-sarscov-20210225152634.html.
3. Cheng Y, Wong R, Soo Y. Use of convalescent plasma therapy in SARS patients in Hong Kong. In Clin Microbiol Infect Dis 2005.; 2005. p. 24.

4. FDA. Autorización de Plasma Convaleciente en Pacientes con covid-19. CDC. 2020 marzo.

5. FDA. "Qué es el Plasma Convaleciente". [Online]; 2020 [cited 2021 enero. Available from: https://www.bbc.com/mundo/ noticias-52129984. 6. Rismanbaf A. Potential Treatments for COVID-19. In.: Acad Emerg Med.; 2020. p. 29.

7. Redacción Médica. Coronavirus: la OMS declara la pandemia a nivel mundial por Covid-19. [Online]; 2020 [cited 2021 Abril. Available from: https://www.redaccionmedica. com/secciones/sanidad-hoy/coronaviruspandemia-brote-de-covid-19-nivel-mundialsegun-oms-1895. 8. Ministerio de Salud. Guía para el manejo del COVID-19. Unidad de Epidemiología. 2020 mayo.

9. Álvarez de Zayas C. Metodología de la Investigación Científica. Cochabamba: Kipus; 2019.

Conflicto de Intereses. Los autores declaran que no existe conflicto de intereses para la publicación del presente artículo científico.

Financiamiento: Autofinanciado.

Agradecimiento: Ninguno declarado por el autor.

\section{ACERCA DEL AUTOR}

Danilo Maida Díaz. Mater en Hematología y Medicina Transfusional. Especialista en Hemoterapia. Responsable Bioquímico del Servicio de Transfusión del Hospital "Presidente Germán Busch". Docente de la Carrera de Medicina de la Universidad Autónoma del Beni "José Ballivián". Docente invitado de Postgrado en la Universidad Autónoma "Juan Misael Saracho". Bioquímico Clínico en Servicio de Transfusión H.P.G.B. Universidad Autónoma del Beni "José Ballivián", Bolivia 